\title{
The changing face of obstetric fistula surgery in Ethiopia
}

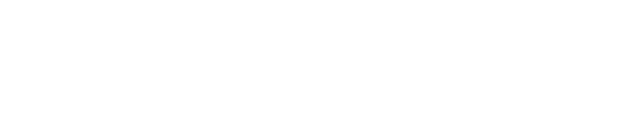

Jeremy Wright ${ }^{1,2}$

Fekade Ayenachew'

Karen D Ballard ${ }^{1,2}$

'Hamlin Fistula Ethiopia, Addis Ababa, Ethiopia; ${ }^{2}$ School of Health Studies, University of Surrey, Guildford, Surrey, UK
Correspondence: Jeremy Wright Kelwood, 2 Jackmans Lane, Woking, Surrey GU2I 7QU, UK

Tel +44 I48 3772510

Email jeremy.wright@surrey.ac.uk

Fekade Ayenachew Hamlin Fistula Ethiopia, PO Box 3609, Addis Ababa, Ethiopia Email ayenachew.f@hamlinfistula.org
Objective: To examine the incidence and type of obstetric fistula presenting to Hamlin Fistula Ethiopia over a 4-year period.

Study design: This is a 4-year retrospective survey of obstetric fistula treated at three Hamlin Fistula Hospitals in Ethiopia, where approximately half of all women in the country are treated. The operation logbook was reviewed to identify all new cases of obstetric fistula presenting from 2011 to 2015 . New cases of urinary fistula were classified by fistula type (high or low), age, and parity of the woman.

Results: In total, 2,593 new cases of urinary fistulae were identified in the study period. The number of new cases fell by $20 \%$ per year over the 4 years $(P<0.001)$. A total of 1,845 cases (71.1\%) were low (ischemic) fistulae, and 804 cases (43.6\%) of these had an extreme form of low circumferential fistula. A total of $638(24.6 \%)$ women had a high bladder fistula, which predominantly occurs following surgery, specifically cesarean section or emergency hysterectomy, and $110(4.2 \%)$ women had a ureteric fistula. The incidence of high fistulae increased over the study period from $26.9 \%$ to $36.2 \%(P<0.001)$. A greater proportion of multiparous women had a high bladder fistula (70.3\%) compared with primigravid women $(29.7 \%)(P<0.001)$. Conversely, a greater proportion of primiparous women experienced a low circumferential fistulae (68.6\%) compared with multiparous women $(31.4 \%)(P<0.001)$.

Conclusion: There appears to be a decline in the number of Ethiopian women being treated for new obstetric urinary fistulae. However, the type of fistula being presented for treatment is changing, with a rise in high fistulae that very likely occurred following cesarean section and a decline in the classic low fistulae that arise following obstructed childbirth.

Keywords: obstetric fistulae, iatrogenic fistulae, Ethiopia, changing incidence, parity

\section{Introduction}

Although significant progress has been made on many of the Millennium Development Goals, many sub-Saharan countries have not been able to achieve Millennium Development Goal 5: to reduce maternal mortality by 75\% (UN 2014). ${ }^{1}$ Ethiopia's efforts to reduce their 10 -year static maternal mortality rate appear to have finally paid off; the latest estimate of 420 maternal deaths per 100,000 live births exists within a relatively peaceful environment with substantial investment in maternal health. ${ }^{2}$

However, in addition to maternal mortality, there is considerable long-term suffering from maternal morbidity. Obstetric fistula, a condition that classically arises when the obstructed fetal head causes prolonged compression of the bladder and vagina on to the symphysis pubis, has been a relatively common phenomenon in rural sub-Saharan African countries. In a study ${ }^{3}$ of the prevalence of vaginal fistula symptoms in 19 sub-Saharan countries through a meta-analysis of Demographic Health Surveys and Multiple Incidence Cluster Surveys, the rate ranged from 0.4 fistula 
per 1,000 women of childbearing age in Burkina Faso to 19.2 fistula per 1,000 women of childbearing age in Uganda. Conflict and infectious disease prevented the collection of data from countries such as the Republic of Sierra Leone and the Republic of Mali. Although the authors quoted a fistula rate of 7.1 per 1,000 women of reproductive age in Ethiopia, without clinical evaluation, these estimates are likely to be higher as other causes of incontinence are not excluded. Indeed, data obtained from a large Ethiopian communitybased study undertaken in 2005 suggested that the prevalence was 2.2 per 1,000 reproductive age women. ${ }^{4}$

Accurate figures of the prevalence of obstetric fistula are also difficult to obtain as women are often reluctant to disclose their condition and tend to isolate themselves. ${ }^{5}$ Given the difficult geopolitical situation in sub-Saharan Africa, the relative prevalence of obstetric fistula remains difficult to accurately assess and the incidence of new cases will fluctuate as a result of conflict or outbreaks of infectious disease, making travel even more difficult.

Since 2005, however, the government of Ethiopia has prioritized maternal health, and in the final two phases of the Health Sector Development Program ${ }^{6}$ took steps to dramatically increase the number of health centers and maternal health professionals and to provide a fleet of ambulances for transferring women in labor to higher level care facilities. Recently published data suggest that these improvements have been effective, with the 2015 prevalence of fistula in Ethiopia dropping to 0.6 per 1,000 reproductive age women. $^{7}$

Simultaneously, the government also increased the number of medical school places and introduced an accelerated training program in emergency surgery and obstetrics for health officers. ${ }^{6}$ A key aim of the Health officer's surgical training program was to produce a new cadre of health professionals, based in rural health facilities and capable of performing cesarean sections. However, the majority of referrals to hospital from the health centers are likely to be women who have been in obstructed labor for many hours, with the uterine cervix being fully dilated and with a fetal malpresentation. In such situations, surgery is likely to be technically challenging, with an increased chance of bladder and ureteric trauma leading to iatrogenic urinary fistula. This paper looks specifically at the proportion of patients with fistulae that apparently follow cesarean section or emergency hysterectomy who subsequently present to Hamlin Fistula Ethiopia for treatment.

Obstetric urinary trauma can be broadly divided into low (Figure 1) or high (Figure 2) urinary fistulae. Low fistulae are traditionally caused by ischemic necrosis as a result of prolonged compression of the lower vagina, urethra, and

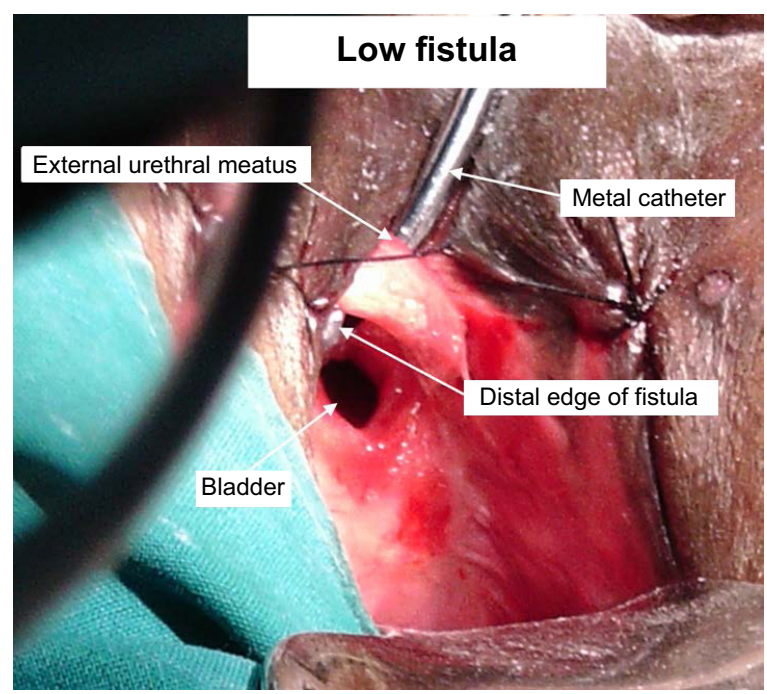

Figure I Intraoperative photograph showing a typical low fistula at the start of surgery.

Notes: Two-thirds of the urethra has been avulsed from the bladder, with only the posterior portion remaining intact. The loss of tissue including the urethral sphincter and part of the bladder base will make complete continence unlikely.

bladder base between the fetal head and the symphysis pubis. Very prolonged compression can lead to a circumferential urethral fistula in which the urethra becomes disconnected from the bladder base with variable but often significant tissue loss. High juxtacervical, intracervical, or ureteric fistula usually, though not always, follows operative intervention such as cesarean section. Low fistulae can also follow a successful cesarean section undertaken to relieve the obstruction, but after tissue necrosis in the lower vagina has occurred. Indeed, in a study of 146 women, Matthieu et $\mathrm{al}^{8}$ reported that two-thirds of the women with a low obstetric fistula following prolonged labor had a cesarean section.

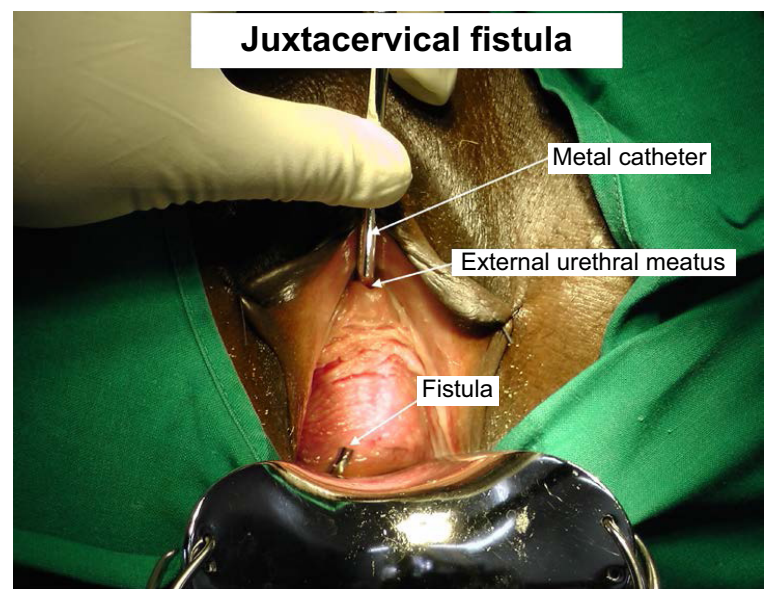

Figure 2 Intraoperative photograph showing a typical high fistula at the start of surgery.

Notes: The defect is small, but with dense circular scarring, and may become bigger when the scar is excised. The urethral sphincter and the bladder base are intact, so the prognosis for eventual complete continence is good. 
There is little evidence about the magnitude of iatrogenic fistula following cesarean section, although Raassen et $\mathrm{al}^{9}$ in a study of 5,959 women with fistulae, from eleven countries over 18 years from 1994, reported that $13.6 \%$ of these women were judged to have an iatrogenic fistula, the majority following cesarean section. Similarly, in a retrospective analysis of 576 women presenting with an obstetric fistula between 2005 and 2007 in the Democratic Republic of the Congo, 229 (40\%) were following cesarean section and 24\% of these were considered to be iatrogenic. ${ }^{10}$

We present a study of secular trends in the changing incidence of low and high obstetric fistula presenting to Hamlin Fistula Ethiopia in Addis Ababa over a 4-year period from January 2011 to December 2014.

\section{Methods}

This is a retrospective review of the surgical logbook in three of the Hamlin Fistula Hospitals: Addis Ababa (capital city), Metu (west Ethiopia), and Yirgalem (south Ethiopia).

\section{The study setting}

Hamlin Fistula Ethiopia is a charitable organization with one main hospital in Addis Ababa, the capital city of Ethiopia, and five outreach hospitals in different areas across the country. The treatment is completely free of charge, with transport costs and any rehabilitation needs also being catered for. It is the largest fistula organization and provides around $80 \%$ of the fistula treatments in Ethiopia. ${ }^{8}$

\section{Participants}

All women attending one of the study hospitals for surgical treatment of a new (previously untreated) obstetric urinary fistula over the 4-year study period were included in the study.

\section{Data collection}

Data relating to the type of fistula, treatment provided, age, and parity were retrieved from the hospital operating logbook where they were routinely recorded.

Patients were placed into the following groups based on age: under 20, 21-25, 26-30, 31-35, 36-40, and greater than 41 years. Parity was grouped as $1,2-4$, and 5 or more.

Fistulae were classified as either low noncircumferential, low circumferential, or high fistula on the basis of the operative record by the principle researcher. High fistulae were further subdivided into whether there was a ureteric injury or not (Table 1). We did not use either of the two main classification systems for obstetric fistula (the $\mathrm{Goh}^{11}$ classification and the Waadijk ${ }^{12}$ system) as both classification systems rely on a great degree of subjectivity, and the
Table I Classification of vesicovaginal fistulae

\begin{tabular}{|c|c|}
\hline $\begin{array}{l}\text { Low } \\
\text { noncircumferential } \\
\text { urinary fistulae }\end{array}$ & $\begin{array}{l}\text { Fistulae involve the low or mid vagina causing } \\
\text { destruction of the bladder base and/or urethra, } \\
\text { which is often associated with reduced bladder } \\
\text { capacity as a result of tissue loss or scarring. }\end{array}$ \\
\hline $\begin{array}{l}\text { Low } \\
\text { circumferential } \\
\text { urinary fistula }\end{array}$ & $\begin{array}{l}\text { Involve the low and mid vagina with complete } \\
\text { separation of the urethra from the bladder, loss } \\
\text { of urethral, smooth muscle, and damage to the } \\
\text { bladder base. Surgery leads to further urethral } \\
\text { scarring, usually a shortened urethra and a failure } \\
\text { of the closure mechanism and stress urinary or } \\
\text { dribbling incontinence. }\end{array}$ \\
\hline $\begin{array}{l}\text { High urinary } \\
\text { fistula }\end{array}$ & $\begin{array}{l}\text { Juxtacervical, intracervical, uterovesical or vault } \\
\text { fistula, including ureteric fistula. Little reduction in } \\
\text { bladder capacity unless the lesion is large }(>5 \mathrm{~cm}) \\
\text { or damage to urethra, though may cause ureteric } \\
\text { obstruction and renal damage. }\end{array}$ \\
\hline
\end{tabular}

fistulae had not been accurately scored at the time of surgery. Moreover, the focus of the classification systems is on the likelihood of postclosure continence rather than etiology, and our study was looking specifically at the changing etiology of vesicovaginal fistula.

\section{Data analysis}

The data were entered into SPSS Version 20 (IBM Corporation, Armonk, NY, USA) for analysis. Descriptive statistics were used to report the rates of fistulae over time. Pearson's chi-squared test was used to determine relationships between parity, age, and fistula type. The Mantel-Haenszel chi-square test was used to test for linear association between the change in fistula type over the 4 years. A $P$-value of $<0.05$ was regarded as significant.

As this was an audit of surgery carried out at a Hamlin Fistula Ethiopia hospital by an employee of that hospital and patient anonymity was preserved, ethical clearance was not considered necessary by the Ethical Committee of Hamlin Fistula Ethiopia. The Ethical Committee of Hamlin Fistula Ethiopia did not require patient consent to be obtained as this was a retrospective study and patient anonymity was preserved.

\section{Results}

\section{The declining incidence of fistulae}

A total of 2,593 new cases of vesicovaginal fistulae were identified in the three study centers over the 4-year period. Overall, the trends were the same in all three centers studied. There was a significant $(P<0.001)$ decline in the annual number of fistula cases throughout the 4-year study period, dropping by $20 \%$ between 2011 and 2012, by a further 13\% from 2012 to 2013, and a further 20\% from 2013 to 2014 (Figure 3). 


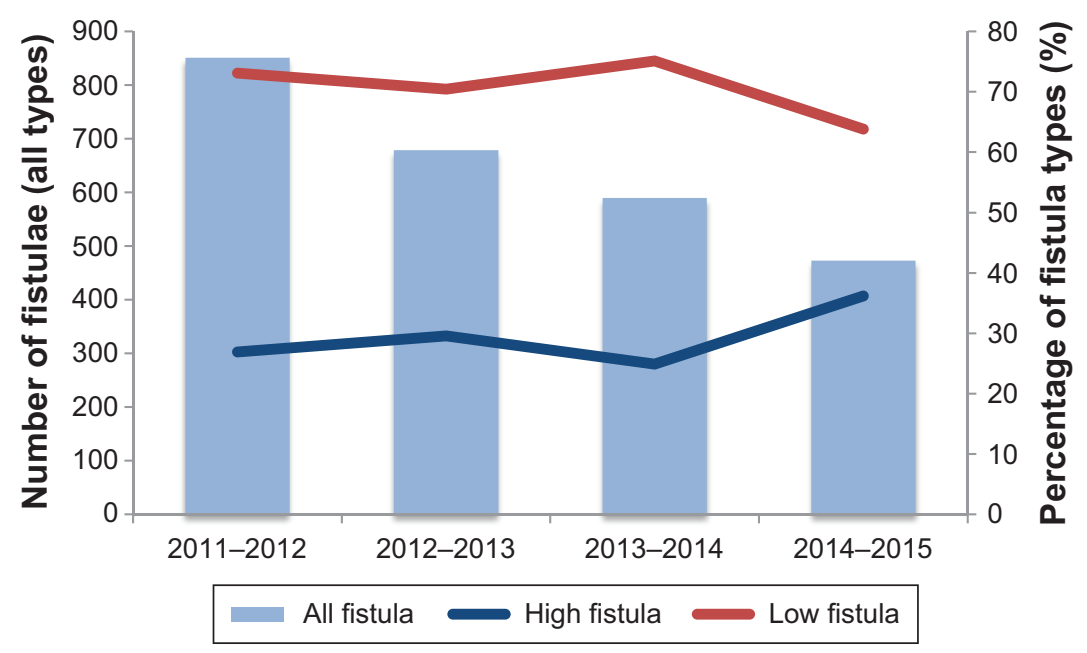

Figure 3 Combined bar and line charts demonstrating declining incidence of new obstetric fistula cases presenting to Hamlin Fistula Ethiopia $201 \mathrm{I}-20 \mathrm{I} 5$ and the changing presentation of low and high fistulae.

Note: The annual changes in numbers and types of fistulae.

As might be expected, there was a strong relationship between low parity and young age: $\chi^{2}=722.372, P<0.001$.

\section{Low fistulae}

The majority of women presented with a low fistula, with 1,041 (41\%) women having a low noncircumferential fistula and $804(31 \%)$ having a low circumferential fistula.

The proportion of low noncircumferential fistula remained fairly constant over the 4 years, whereas the proportion of low circumferential fistulae declined over the study years, with $36.5 \%$ of the cases being low circumferential in 2011-2012, reducing to $26.8 \%$ in $2014-2015(P<0.001)$.

A greater proportion of primiparous women (68.6\%) had a low circumferential fistula compared with multiparous women $(31.4 \%)(P<0.001)$. Parity, however, was not related to the presence of a low noncircumferential fistula, with similar proportions of primiparous women $(46.7 \%)$ and multiparous women $(43.3 \%)$ presenting with low noncircumferential fistulae (Table 2).

\section{High fistulae}

A total of 638 (24.6\%) women had a high bladder fistula, and $110(4.2 \%)$ women had a high ureteric fistula.

The proportion of high fistula increased over the years, with $26.9 \%$ of the cases being high fistula in 2011-2012 and
$36.2 \%$ in $2014-2015(P<0.001)$. There was a significant linear association between the increasing annual rate of high fistula and decreasing annual rate of low fistula over the years $(P=0.014)$.

A greater proportion of multiparous women had a high bladder fistula (70.3\%) compared with primigravid women (29.7\%) $(P<0.001)$.

\section{Discussion}

\section{Principle findings}

Although this study reports a decline in the overall number of new cases of urinary fistula presenting for treatment, the type of fistula is changing, with an increased proportion of high, iatrogenic fistulae and a decreased proportion of low fistula.

Of particular note is the decline in the proportion of low circumferential fistulae, which are largely experienced by young primiparous women and are associated with exceptionally poor treatment outcome. ${ }^{14}$ Iatrogenic fistulae, on the other hand, are generally associated with good treatment outcome, with the vast majority being cured by their surgery. ${ }^{9}$ The implication of this study, however, is that women are increasingly able to reach a place of treatment before an ischemic low fistula can occur, but some are now suffering an iatrogenic high fistula as the necessary skills or facilities

Table 2 Fistula type by parity

\begin{tabular}{lllll}
\hline Parity & Low noncircumferential & Low circumferential & High bladder & Ureteric \\
\hline Primigravid & $453(46.7 \%)$ & $409(68.6 \%)$ & $175(29.7 \%)$ & $9(22 \%)$ \\
Para 2-4 & $331(34.2 \%)$ & $138(23.2 \%)$ & $286(48.6 \%)$ & $18(43.9 \%)$ \\
Para 5 or more & $185(19.1 \%)$ & $49(8.2 \%)$ & $128(21.7 \%)$ & $14(34.1 \%)$ \\
Total & 969 & 596 & 589 & $4 \mid$ \\
\hline
\end{tabular}


to perform a cesarean section for obstructed labor when the presenting part is impacted and causing necrosis as a result of soft tissue compression.

\section{Strengths and weaknesses}

This is the first large study reporting changes in the types of new fistula being presented for treatment over a period of 4 years.

Although our data reflect a large proportion of the fistula treatments being provided in Ethiopia, the findings are limited to the population seeking treatment at three Hamlin hospitals rather than the population seeking fistula treatment across the whole of Ethiopia. There are, however, only two main organizations providing the vast majority of fistula treatment within Ethiopia, and the Hamlin Fistula Ethiopia provides around $80 \%$ of the care. ${ }^{12}$ Moreover, although we only have data from three of the six Hamlin hospitals, these hospitals represent about two-third of the fistula workload within Hamlin, and the patterns are likely to be similar in the other centers. We are, of course, unable to report on the types of fistula experienced by women who do not present for treatment.

\section{Interpretation and relation to other data}

Since Hamlin Fistula Ethiopia is the biggest provider of fistula care across Ethiopia, our finding of an annual reduction in number of women attending for treatment of a new fistula points toward an overall national decline in fistula prevalence. This, however, may not be the case in other sub-Saharan countries where access to medical care is even poorer, although the study by Matthieu et $\mathrm{al}^{8}$ suggests that in areas where there is some, if limited access to cesarean section, there is still a significant proportion of women still developing a low obstetric fistula despite surgery suggesting that referral may be delayed. Indeed, a recent large community-based study in Ethiopia in which the fistula was confirmed by clinical examination reports a fistula prevalence of 0.6 per 1,000 reproductive age women, ${ }^{7}$ which is a sizeable reduction from the 2.2 per 1,000 reproductive age women reported in $2005 .^{4}$

The overall decline in the number of new cases by around $50 \%$ is gratifying, and the decreasing percentage of low fistulae suggests that women are gaining access to help earlier when labor becomes obstructed. The increased provision of maternal health services, improved road infrastructure, and availability of ambulances in rural areas will have undoubtedly contributed greatly to these improvements. As and when similar conditions can be established in more troubled areas of sub-Saharan Africa, it is hoped that similar declines in incidence will be observed. It is however important to recognize that while the rate of low circumferential fistulae is on the decline, our data show that this type of fistula is predominantly experienced by young women under the age of 25 years, with one-third of the women being under the age of 20 years.

The chances of ever achieving complete continence following a circumferential fistula are poor, ${ }^{14}$ and therefore, helping women and health care professionals to recognize the signs of obstructed labor and improving the referral process to appropriate health facilities is paramount. In addition to the appalling maternal trauma, stillbirth is almost always associated $^{3}$ with loss of life and increasing misery. A recent study of fistula patients ${ }^{15}$ has suggested that a simple and easily performed assessment of the pelvic outlet size could identify the group of women at particular risk of disproportion. Identifying women at particular risk of fistula during antenatal assessment and encouragement to deliver their baby in a health facility might further reduce the number of women presenting with circumferential fistula.

The increasing number of high fistula is more difficult to explain, and previous surgery, either cesarean section or hysterectomy, was not routinely recorded, although given our finding that high fistula was more common in multiparous women, it is likely that the fistulae occurred following operative deliveries for malpresentation at full cervical dilatation for many hours or following uterine rupture rather than absolute bony disproportion. In either of these situations, the delivery will be technically very challenging and probably beyond the capacity of newly qualified doctors with limited surgical experience or surgically trained health officers.

Although there appears to be limited evidence about the incidence of iatrogenic obstetric fistula, a recent systematic review and meta-analysis of six sub-Saharan African studies investigating maternal and perinatal outcomes following cesarean section by doctors and surgical health officers found that while there was an increased risk of wound infections and dehiscence among women whose cesarean section was performed by surgically trained health officers, there was no increased maternal or perinatal mortality. ${ }^{16}$ None of the studies reported data on iatrogenic fistula. Moreover, only one study reported on the years of experience that the doctors and health officers had, and it may be possible that outcomes equalize only after several years of practice.

\section{Future directions}

Ensuring that there are appropriately trained and skilled obstetricians in rural areas is a particular challenge, but addressing both this and the detection of pelvic contraction would have the potential to make the reduction in obstetric fistula the rarity it should be. These figures also point to the 
need for an audit of indications for and outcome of cesarean sections performed in these health facilities, similar to the maternal death surveillance programs now being carried out. Repair of high fistulae, though technically challenging, has good prognostic functional outcomes, as the bladder base and urethra are not irretrievably damaged. Low and circumferential fistulae occur in young women and despite treatment have much poorer outcomes in terms of persistent problems with incontinence. Ethiopia has made significant steps to reduce obstetric fistula. ${ }^{13}$ Other sub-Saharan countries should be able to follow suit. Early recognition of obstruction or malpresentation and prompt competent surgery would solve the problem of obstetric fistula.

\section{Conclusion}

While the overall incidence of obstetric fistula appears to be declining, the number of women having iatrogenic fistulae has increased over the past few years. The reduction in fistula has likely arisen from increased uptake of maternal health services for delivery. However, the increase in iatrogenic fistula suggests that women may be presenting late at health facilities and requiring complex cesarean sections. Although surgical training for health officers offers a possible solution, they may not yet have the experience to undertake complex cesarean deliveries in what are often difficult surgical circumstances.

\section{Disclosure}

The authors report no conflicts of interest in this work.

\section{References}

1. WHO, The World Bank and United Nations Population Division. Trends in Maternal Mortality: 1990 to 2013. Geneva, Switzerland: World Health Organization; 2014:56.
2. Ethiopian Ministry of Health (Ethiopia) Health Sector Development Central Statistical Agency [Ethiopia] and ICF International. Ethiopia Demographic and Health Survey 2011. Addis Ababa, Ethiopia and Calverton, Maryland: Central Statistical Agency and ICF International; 2012.

3. Maheu-Giroux M, Filippi V, Samadoulougou S, et al. Prevalence of symptoms of vaginal fistula in 19 sub-Saharan Africa countries: a metaanalysis of national household survey data. Lancet Glob Health. 2015; 3(5):e271-e278.

4. Muleta M, Fantahun M, Tafesse B, Hamlin EC, Kennedy RC. Obstetric fistula in rural Ethiopia. East Afr Med J. 2007;84(11):526-534.

5. Ahmed S, Holtz SA. Social and economic consequences of obstetric fistula: life changed forever? Int J Gynecol Obstet. 2007;99:S10-S15.

6. Ethiopian Ministry of Health (Ethiopia). Health Sector Development Program IV 2010/11-2014/15. Addis Ababa, Ethiopia; 2010. Available from: http://www.nationalplanningcycles.org/sites/default/files/ country_docs/Ethiopia/ethiopia_hsdp_iv_final_draft_2010_-2015.pdf. Accessed September 7, 2015.

7. Ballard K, Ayenachew F, Wright J, Atnafu H. Prevalence of obstetric fistula and symptomatic pelvic organ prolapse in rural Ethiopia. Int Urogynecol J. 2016;27(7):1063-1067.

8. Matthieu LN, Jean N, Gunter DW, Dieter O, Augustin PM, Dirk DR. Obstetric fistula in a district hospital in DR Congo: fistula still occur despite access to caesarean section. Neurourol Urodyn. 2015;34(5):434-437.

9. Raassen TJ, Ngongo CJ, Mahendek MM. Iatrogenic genitourinary fistula: an 18 year retrospective review of 805 injuries. Int $J$ Obstet Gynaecol. 2014;25(12):170.

10. Onsrud M, Sjoveian S, Mukwege D. Caesaren delivery-rated fistulae in the Democratic Republic of Congo. Int J Gynaecol Obstet. 2011; 114(1):10-14.

11. Goh JWT, Krause HG. Female Genital Tract Fistula. Brisbane, Queensland: University of Queensland Press; 2004.

12. Waadijk K. Step by Step Surgery of Vesico-vaginal Fistulas. Edinburgh, Scotland: Campion Press; 1994.

13. Fauveau V, Muleta M. Restoring Happiness: An Assessment of the Fistula Situation in Ethiopia in 2013. Washington, DC: USAID; 2013.

14. Wright J. Circumferential urethral fistulae in Sub-Saharan Africa, current outcomes and future prospects. Int Urogynecol J. 2014;26(8): 1209-1212.

15. Browning A, Lewis A, Whiteside S. Predicting women at risk for developing obstetric fistula: a fistula index? An observational study comparison of two cohorts. BJOG. 2014;121:604-609.

16. Wilson A, Lissauer D, Thangaratinam S, Khan K, MacArthur C, Coomarasamy A. A comparison of clinical officers with medical doctors on outcomes of caesarean section in the developing world: meta-analysis of controlled studies. BMJ. 2011;342:d2600.
International Journal of Women's Health

\section{Publish your work in this journal}

The International Journal of Women's Health is an international, peerreviewed open-access journal publishing original research, reports, editorials, reviews and commentaries on all aspects of women's healthcare including gynecology, obstetrics, and breast cancer. The manuscript management system is completely online and includes

\section{Dovepress}

a very quick and fair peer-review system, which is all easy to use. Visit http://www.dovepress.com/testimonials.php to read real quotes from published authors. 